Subglottic haemangioma in children: experience with open surgical excision

J Laryngol Otol 2006;120:1033-7

Dear Sirs

Bajaj and colleagues present an excellent paper ${ }^{1}$ describing their approach to the management of subglottic haemangioma. We agree wholeheartedly with their treatment philosophy, but would like to offer a few points in addition.

The one failure ('partial success') in their series was in a premature baby ( 34 weeks corrected gestational age at the time of operation, not 34 weeks old as stated in the article), who was originally thought to have an isolated subglottic haemangioma and who therefore underwent a singlestage, open submucosal excision. However, the lesion proved to be part of a larger haemangioma of the face and neck, with an extensive, infiltrating subcutaneous component. We have also encountered a similar patient in Glasgow; a full-term neonate who underwent a singlestage, open submucosal excision of what we believed to be a haemangioma confined to the subglottis, but which subsequently proved to be part of an extensive, infiltrating cutaneous haemangioma of the face and neck (Figure 1). The lesion extended from the skull base to the mediastinum (Figure 2), and significant symptoms of airway obstruction recurred soon after surgery (incidentally, also the only failure or 'partial success' in our experience of excision of subglottic haemangiomas so far). Other authors have also reported a child who underwent excision of a subglottic haemangioma which proved to be part of a larger lesion and which required further treatment. ${ }^{2}$

Would the authors agree that, although excision is the treatment of choice for lesions confined to the subglottis, extreme care should be exercised in children who also have large, infiltrating cutaneous haemangiomas, even when these initially appear to be separate from the subglottic lesion?

The child we describe above responded dramatically to treatment with vincristine. The stridor disappeared and

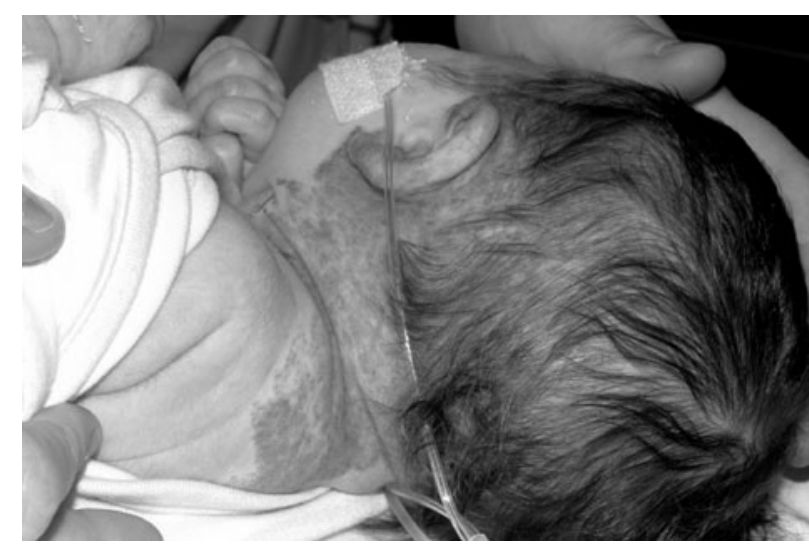

FIG. 1

The neonate described, showing extensive cutaneous haemangioma involving the left side of the face and neck.

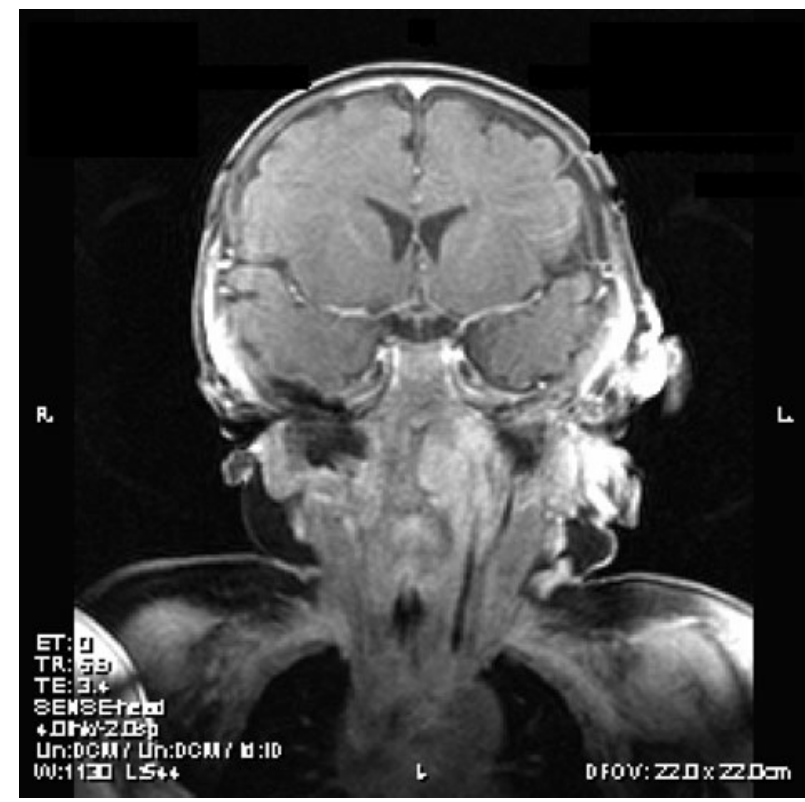

FIG. 2

Coronal T1-weighted magnetic resonance imaging scan, showing haemangioma throughout the left side of the neck.

tracheostomy was avoided. The child in the French series was also treated with vincristine, to good effect. ${ }^{2}$ Do Bajaj and colleagues agree that vincristine may prove to have a role in the management of these more extensive and difficult lesions?

\section{H Kubba}

D Murphy

From the Royal Hospital for Sick Children, Glasgow, Scotland, UK.

\section{References}

1 Bajaj Y, Hartley BEJ, Wyatt ME, Albert DM, Bailey CM. Subglottic haemangioma in children: experience with open surgical excision. J Laryngol Otol 2006;120:1033-7

2 Enjolras O, Breviere GM, Roger G, Tovi M, Pellegrino B, Varotti E et al. Vincristine treatment for function- and lifethreatening infantile haemangioma [in French]. Arch Pediatr 2004;11:99-107

\section{Authors' reply}

Dear Sirs

We would like to thank Kubba and Murphy for these comments.

We agree that caution should be exercised when undertaking subglotttic surgery for more extensive lesions with cutaneous haemangiomas. It should, however, still be seriously considered as a simple, quick and low-morbidity treatment, compared with the alternatives in this situation, which include tracheostomy or 
intense medical treatment, possibly with vincristine ${ }^{1}$ or interferon alpha. ${ }^{2}$

Tracheostomy carries the risk of significant morbidity in a neck with extensive haemangioma, and also significant mortality. It should be avoided if possible. It is likely to be present for several months or years.

The worldwide experience of using vincristine to reduce mass in haemangiomas with airway obstruction is limited to a handful of cases. ${ }^{1,3}$ The treatment is a major undertaking for the family, with multiple courses of chemotherapy via a long intravenous line over several weeks, and the response is unpredictable. There are significant potential side effects.

We have had some apparent success with this treatment in two cases, but would urge extreme caution before advocating it without further data and proper analysis.
Y Bajaj

B Hartley

From the Great Ormond Street Hospital for Children, London, UK.

\section{References}

1 Enjolras O, Breviere GM, Roger G, Tovi M, Pellegrino B, Varotti $\mathrm{E}$ et al. Vincristine treatment for function- and lifethreatening infantile haemangioma [in French]. Arch Pediatr 2004;11:99-107

2 Grimal I, Duveau E, Enjolras O, Verret JL, Ginies JL. Effectiveness and dangers of interferon-alpha in the treatment of severe hemangiomas in infants [in French]. Arch Pediatr 2000;7:163-7

3 Perez J, Pardo J, Gomez C. Vincristine - an effective treatment of corticoid-resistant life threatening infantile haemangiomas. Acta Oncol 2002;41:197-9 